\title{
XXI. Mechanical integration of the product of two functions
}

\author{
William Sutherland M.A. B.Sc.
}

To cite this article: William Sutherland M.A. B.Sc. (1885) XXI. Mechanical integration of the product of two functions, Philosophical Magazine Series 5, 20:123, 175-178, DOI: $10.1080 / 14786448508627740$

To link to this article: http://dx.doi.org/10.1080/14786448508627740

曲 Published online: 29 Apr 2009.

Submit your article to this journal

Џ Article views: 7

Q View related articles $\square$ 


\section{$\left[\begin{array}{ll}175 & ]\end{array}\right.$}

XXI. Mechanical Integration of the Product of two Functions. By William SutherLand, M.A., B.Sc.*

TN a communication to the Royal Society (February 3, 1 1876), " On an Instrument for Calculating $\int \phi(x) \psi(x) d x$, the integral of the product of two Functions," Prof. Sir William Thomson has shown how, by the use of Prof. James Thomson's disk, globe, and cylinder integrating machine, the integral of the product of two functions can be found. The operations involved consist, first, in plotting the curve $y=\psi(x)$, then in making the instrument, by a rather difficult attachment, yield a trace of the curve $y=\int_{0}^{x} \psi(x) d x$, then in plotting the curve $y=\phi(x)$ : these two latter curves have to be wrapped round one or two cylinders. When the cylinders are caused to revolve, a pointer capable of moving parallel to the axis of $y$ has to be kept on each curve, the motions of the two pointers being communicated to the disk and globe respectively of the integrator : the amount of the angular movement of the cylinder gives the integral.

In view of the very important part that the analysis of an arbitrary function into its harmonic constituents is destined to play in extracting law out of the immense mass of physical and chemical measurements that are being accumulated, it seemed to be worth while to look for a simpler method of obtaining $\int \phi(x) \psi(x) d x$ than the above. The following may be found to be such, and seems likely to be capable of more immediate application ; for the disk, globe, and cylinder integrator, despite its kinematical elegance, has not yet come into general use.

The following method is merely a mechanical realization of the operations which Fourier so carefully describes in his 'Analytical Theory of Heat,' art. 220, chap. iii. sect. vi., in order to give as concrete an idea as possible of the meaning of the coefficients in his expansion. "We see by this that the coefficients $a, b, c, d, e, f$ which enter into the equation

$$
\frac{1}{2} \pi \phi(x)=a \sin x+b \sin 2 x+c \sin 3 x+d \sin 4 x+\& c .,
$$

and which we found formerly by successive eliminations are the values of the definite integrals expressed by the general term $\int \sin i x \phi(x) d x, i$ being the number of the term whose coefficient is required. This remark is important, because it shows how even entirely arbitrary functions may be developed in series of sines of multiple ares. In fact, if the function $\phi(x)$ be represented by the variable ordinate of any curve * Communicated by the Author. 
whatever, whose abscissa extends from $x=0$ to $x=\pi$, and if in the same part of the axis the known trigonometrical curve whose ordinate is $y=\sin x$ be constructed, it is easy to represent the value of any coefficient. We must suppose that for each abscissa $x$ to which corresponds one value of $\phi(x)$ and one value of $\sin x$, we multiply the latter value by the first, and at the same point of the axis raise an ordinate equal to the product $\phi(x) \sin x$. By this continuous operation a third curve is formed, whose ordinates are those of the trigonometrical curve reduced in proportion to the ordinates of the arbitrary curve which represents $\phi(x)$. This done, the area of the reduced curve taken from $x=0$ to $x=\pi$ gives the exact value of the coefficient of $\sin x . "$

To take the more general case, let it be required to find $\int_{a_{1}}^{a_{2}} \phi(\theta) \psi(\theta) d \theta$. Plot the two curves whose polar equations are $r=\phi(\theta), r=\psi(\theta)$, using the same pole and the same initial line for angular measurement in both cases. Let $S_{1}$ and $S_{2}$ be the points on the two curves corresponding to any value of $\theta$ (see figure); then

$$
\psi(\theta) \phi(\theta)=0 \mathrm{~S}_{1} . \mathrm{OS}_{2} \text {. }
$$

Describe a circle of radius $R$ passing through $S_{1}$ and $S_{2}$; through $\mathrm{O}$ draw the tangent $\mathrm{OT}$ to this circle, then

$$
\mathrm{OT}^{2}=\mathrm{OS}_{1} \cdot \mathrm{OS}_{2} \text {. }
$$

Now if the arm $0 S_{1} S_{2}$ is turned into any other position, cutting the curves in two fresh points $\mathbb{S}_{1}^{\prime}$ and $\mathbf{S}_{2}^{\prime}$, and if the circle of constant radius $R$ is again brought into position so as to pass through these points, the new length of the tangent $\mathrm{OT}^{\gamma}$ is always such that $\mathrm{OT}^{\prime 2}=\mathrm{OS}_{1}^{\prime}$. $\mathrm{OS}_{2}^{\prime}$ : therefore generally $\mathrm{OT}^{2}=\psi(\theta) \phi(\theta)$.

In $\mathrm{OS}_{1} \mathrm{~S}_{2}$ mark off $\mathrm{OS}_{3}=\mathrm{OT}$; then if, as $\mathrm{OS}_{1} \mathrm{~S}_{2}$ is revolved

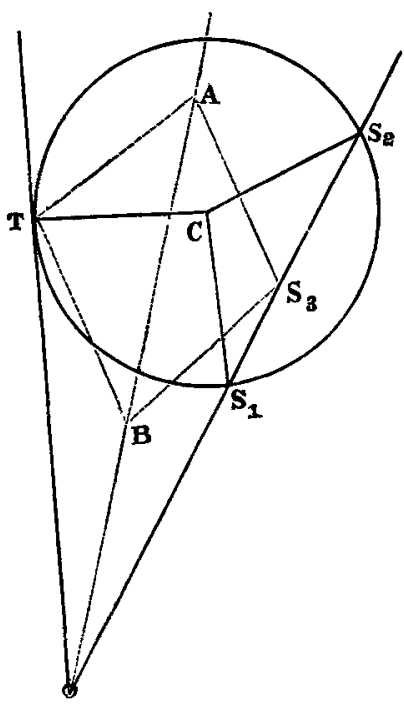
from the Initial to the final position, or from that given by $\theta=\alpha_{1}$ to that by $\theta=\alpha_{2}$, the motion of $\mathrm{T}$ is by any mechanical device communicated to $S_{3}$ unaltered, the locus of $S_{3}$ is a curve such that always $\mathrm{OS}_{3}^{2}=\phi(\theta) \psi(\theta)$;

$$
\therefore \int_{\alpha_{1}}^{a_{2}} \phi(\theta) \psi(\theta) d \theta=\int_{a_{1}}^{\alpha_{2}} \operatorname{OS}_{3}^{2} d \theta
$$


$=$ twice the area of the figure enclosed by the third curve traced out by $S_{3}$, and by the lines $\theta=\alpha_{1}, \theta=\alpha_{2}$.

The arrangements for describing the third curve mechanically are obrious. An arm, $0 \mathrm{~S}_{1} \mathrm{~S}_{2}$, capable of turning freely in the plane of the paper round an axis through $O$, bears two collars, $S_{1}$ and $S_{2}$, free to move along $O S_{1} S_{2}$; and to these, two equal arms, $\mathrm{S}_{1} \mathrm{C}, \mathrm{S}_{2} \mathrm{C}$, are freely jointed, being at the same time each free to turn in the plane of the paper round an axis through $\mathrm{C}$; the two collars bear pointers with which to follow the two curves. A second long arm, OT, can turn round the axis through $\mathrm{O}$; at $\mathrm{T}$ is a collar free to move along $\mathrm{OT}$, and to it is rigidly attached an arm, CT, equal to $\mathrm{CS}_{1}$ and $\mathrm{CS}_{2}$, and always at right angles to OT: this arm bear's the axis through $C$. Then as $S_{1}$ and $S_{2}$ are guided along the corresponding curves, the two arms OT and CT move in such a manner that $T$ is always the point in which a circle of radius $\mathrm{CS}_{1}, \mathrm{CS}_{2}$, or $\mathrm{CT}$ is touched by $\mathrm{OT}$; thus always $\mathrm{OT}^{2}=\mathrm{OS}_{1} . \mathrm{OS}_{2}$.

As regards the transmission of the motion of $\mathrm{T}$ to a point $\mathrm{S}_{3}$ on the axis $\mathrm{OS}_{1} \mathrm{~S}_{2}$ different methods are possible, perhaps the simplest being that represented by the dotted lines in the figure. $\mathrm{ATBS}_{3}$ is a rhombus with hinges at the four angular points; the hinges at $\mathrm{T}$ and $\mathrm{S}_{3}$ are attached to the collars there, while the hinges at $A$ and $B$ bear two collars free to move along an arm OBA, which in its turn is free to move round the axis through $\mathrm{O}$, obviously always $\mathrm{OS}_{3}=\mathrm{OT}$. A pencil attached to the collar $S_{3}$ traces the required curve.

All that is necessary, then, for finding the integral

$$
\int_{\alpha_{1}}^{\alpha_{2}} \phi(\theta) \psi(\theta) d \theta
$$

is to join the two ends of this curve by straight lines to $O$ and take the area of the resulting figure by means of any planimeter.

But a very simple attachment to the above mechanism makes a planimeter of it. Suppose the area of any figure to be required. Fix the collar $\mathrm{S}_{1}$ at a certain suitable distance $b$ from $O$, so that when the arm $\mathrm{OS}_{1} \mathrm{~S}_{2}$ moves, $\mathrm{S}_{1}$ must describe a circle of known radius $b$. Guide $S_{3}$ along the outline of the figure, then $\mathrm{S}_{2}$ moves always in such a way that

$$
\int \mathrm{OS}_{3}^{2} d \theta=\int \mathrm{OS}_{1} \cdot \mathrm{OS}_{2} d \theta=b \mathrm{jOS}_{2} d \theta ;
$$

but this last integral is the length of the path travelled by $S_{2}$. Thus all that is necessary is to attach at $S_{2}$ a wheel which will record the length of the path traversed by $S_{2}$.

The whole operation, then, of finding $\int_{\alpha_{1}}^{\alpha_{z}} \phi(\theta) \psi(\theta) d \theta$

Phil. Mag. S. 5. Vol. 20. No. 123. August 1885. N 
resolves itself into the plotting of the two curves $r=\phi(\theta)$, $r=\psi(\theta)$, between the limits $\theta=\alpha_{1}, \theta=\alpha_{2}$, the fixing of the instrument so that its axis passes through $O$, the pole chosen in plotting the curves, the driving of the two pointers $S_{1}$ and $\mathrm{S}_{2}$ along the two curves (which is easily done by one person) causing $\mathrm{S}_{3}$ to trace a third curve between the same limits; then the clamping down of $S_{1}$, the forcing of $S_{3}$ to follow back its former track, and the reading of the revolutions of the wheel attached at $S_{2}$ during this last part of the performance. This reading gives the required value of the integral when the scales on which the two curves were drawn are taken into account. These scales must be chosen so that the maximum difference between ${ } S_{1}$ and $O S_{2}$ shall at least not be greater than the diameter of the circle whose radius is $\mathrm{CS}_{1}$. In the above description, the word collar is used to mean any form of connection that allows with as little friction as possible one degree of relative freedom.

Melbourne, June 1, 1885.

XXII. On the Sensitiveness of Selenium to Light, and the Development of a similar Property in Sulphur. By SHELFORD BIDWELL, M.A., LL.B.**

THE remarkable property apparently possessed by crystal1 line selenium of having its electrical resistance varied by the action of light, a property which was first announced by Mr. Willoughby Smith in 1873, has been the subject of many investigationst. Of these the best known, and by far the most exhaustive, are the researches of Prof. W. G. Adams and Mr. R. E. Day, an account of which is published in the Phil. Trans. of 1877. As the result of numerous experiments, these gentlemen were led to form the opinion, that "the electrical conductivity of selenium is electrolytic" $\neq$. The principal reasons given for this conclusion are:-(1) that the resistance of the selenium-bars used appeared to depend upon

* Communicated by the Physical Society; having been read at the Meetings on May 23 and June 13.

+ Willoughby Smith, Journ. Soc. Tel. Eng. ii. p. 31 ; Earl of Rosse, Phil. Mag. March 1874, p. 161 ; Sale, Proc. Roy. Soc. 1873, p. 283; Phil. Mag. March 1874; Werner Siemens, Phil. Mag. November 1875, p. 416; Draper and Moss, 'Chemical News,' xxxiii. p. 1 ; Adams and Day, Proc. Roy. Soc. 1876, p. 113; Phil. Trans. 1877, p. 313 ; C. W. Siemens, Proc. Roy. Inst. 1876, p. 68; Sabine, Phil. Mag. June 1878, p. 401 ; Graham Bell, 'Nature,' xxii. p. 500 ; Shelford Bidwell, Phil. Mag. April 1881, and January 1883; Fritts, 'Electrical Review' March 7, 1885, p. 208.

$\ddagger$ Phil. Trana. vol. 167, p. 328 ; Proc. Roy. Soc. 1876, p. 115. 